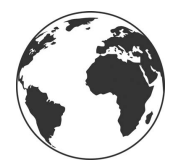

cambridge.org/enc

\section{Research Paper}

Cite this article: Bisi F, Gagliardi A, Cremonesi G, Colombo R, Mazzamuto MV, Wauters LA, Preatoni DG, Martinoli A (2019) Distribution of Wildlife and Illegal Human Activities in the Lampi Marine National Park (Myanmar). Environmental Conservation 46: 163-170. doi: 10.1017/S0376892918000486

Received: 22 May 2018

Accepted: 13 December 2018

First published online: 14 January 2019

\section{Keywords}

camera trap; MaxEnt; patrolling; mammals; tropical forest; poaching

\section{Author for correspondence:}

Dr Francesco Bisi, Email: francesco.bisi@gmail. com

\title{
Distribution of Wildlife and Illegal Human Activities in the Lampi Marine National Park (Myanmar)
}

\author{
Francesco Bisi ${ }^{1,2}$, Alessandra Gagliardi ${ }^{1,2}$, Giacomo Cremonesi ${ }^{1}$, Roberto \\ Colombo $^{3}$, Maria Vittoria Mazzamuto ${ }^{1}$, Lucas Armand Wauters ${ }^{1}$, Damiano \\ Giovanni Preatoni ${ }^{1}$ and Adriano Martinoli ${ }^{1}$
}

\begin{abstract}
${ }^{1}$ Unità di Analisi e Gestione delle Risorse Ambientali - Guido Tosi Research Group - Dipartimento di Scienze Teoriche e Applicate, Università degli Studi dell'Insubria, Via J. H. Dunant, 3 - I-21100 Varese, Italy, ${ }^{2}$ Istituo Oikos, Via Crescenzago 1, 20134 Milan, Italy and ${ }^{3}$ Dipartimento di Scienze dell'Ambiente e della Terra, Università degli Studi di Milano-Bicocca, Piazza della Scienza, 1-20126, Milan, Italy
\end{abstract}

\section{Summary}

Asian tropical forests are among the most affected by overhunting of wildlife species. Bushmeat is not just a source of food, but is also often seen as an income source due to the increasing regional demand for wildlife products. In this study, we assess for the first time the medium- and large-size vertebrate species present in Lampi Marine National Park (Myanmar) using camera traps and opportunistic sightings, and we use data from law enforcement patrolling to identify areas where poaching activities occur. Nineteen different terrestrial vertebrate species were observed in the Park, five of which are listed as globally threatened, while illegal activities were recorded at 107 locations. We estimated wildlife and human distributions using the maximum-entropy (i.e., MaxEnt) algorithm. Human activities were widely distributed in the Park, and areas selected by people were those at lower elevations and mainly in evergreen or semi-evergreen forests where most of the species occur. These models could improve knowledge of species presence and of the potential risk to wildlife associated with human activities. The modelling of wildlife and human presence proved to be useful for identifying areas that would receive special attention during patrolling, management and conservation actions.
(C) Foundation for Environmental Conservation 2019.

\section{CAMBRIDGE} UNIVERSITY PRESS

\section{Introduction}

Determining species presence and distribution is not only useful to ecological research (Rosenzweig 1995, Elith et al. 2006, Graham et al. 2006), but can also be of great importance in environmental impact assessments (Pearson \& Dawson 2003) and conservation action plans (Margules \& Pressey 2000, Ferrier 2002, Funk \& Richardson 2002). In this context, medium to large vertebrates in tropical forests are a priority because of their ecosystem role (e.g., seed predation and dispersal, predator of herbivore species) and because they are often threatened by habitat loss and fragmentation (Ceballos et al. 2005, Ahumada et al. 2011, Visconti et al. 2011). Asian tropical forests in particular are among the most affected by illegal activities, particularly overhunting (Vié et al. 2009). Hunting of wildlife in Southeast Asia has occurred for thousands of years, mainly for nutritional and economic reasons (Fa et al. 2002, Corlett 2007), but wild meat is not just a source of food - it has also become an important income source due to the increasing regional demand for wildlife products backed by an illegal market such as traditional medicine, pets, trophies and decorations (Rao et al. 2005, Corlett 2007). Moreover, in Southeast Asia, forest logging, both in unprotected and - illegally - in protected areas, has resulted in growing human access to forests and increasing hunting pressures both for trade and for provision of food for loggers camping in the forest (Meijaard et al. 2005). Hunters, even if they sometimes have access to new technologies, such as guns and flashlights, often still use unselective snares and traps that require less effort and time than active hunting, which can cause shifts in the faunal species composition (Jerozolimski \& Peres 2003, Corlett 2007). This process affects even more vulnerable habitats such as islands, which are frequently affected by introduced species, overexploitation of resources and habitat destruction (Fordham \& Brook 2010). Wildlife exploitation has reduced the range and abundance of many island species in Southeast Asia, directly causing severe biodiversity loss at a local scale (Brook et al. 2003). In Myanmar, for example, hunting and habitat loss have been largely responsible for the depletion of large mammals from many protected areas (Milton \& Estes 1963, Aung et al. 2004, Rao et al. 2005, 2010). 
The establishment of protected areas does not prevent illegal activities and wildlife decline without an effective management plan, patrol activity and local community awareness (Rao et al. 2002, Jenks et al. 2012, Laurance et al. 2012, Di Marco et al. 2014). In Myanmar, Lampi Marine National Park (LMNP) was established in 1996, but the lack of effective management for a long time (a member of permanent park staff was allocated to LMNP only in 2013) has allowed illegal human activities and settlements to increase over time. LMNP is the only protected area in the Myeik Archipelago. It is an Important Bird Area (IBA), it has been an Association for Southeast Asian Nations (ASEAN) heritage site since 2003 and it was proposed by the Ministry of Environmental Conservation and Forestry (MOECAF) as an UNESCO World Heritage Site in 2014. LMNP includes a variety of pristine terrestrial habitats important for maintaining a high level of diversity of terrestrial wildlife. The Park area also provides food, water and wood (used as fuel as well as raw material for the construction of boats and houses) to the local population of $c$. 2600 people in five settlements. Fishing is the most important economic activity of the area, but hunting is an illegal business that seems to be very lucrative - although not always directly for local people, who most of the time hunt just for subsistence consumption, but especially for people coming from outside the island to hunt and sell mouse deer, pangolins, wild pigs and common water monitors to fishing boats or to local markets inland (Soe et al. 2010). The first park management plan, officially approved in 2014 by MOECAF, highlights the importance of the area for biodiversity conservation, recreational activities, scientific research and education. Hence, the main aim of this study is to identify areas where illegal activities occur and where they can be more problematic for wildlife conservation.

Species distribution models (SDMs) are tools used to predict species distributions in relation to environmental covariates such as habitat or climate (Elith et al. 2006, Linkie et al. 2006, Phillips et al. 2006, Cayuela et al. 2009, Guisan et al. 2013, Gomes-Vale et al. 2016). In the scientific literature, there are few bridges between SDM theory and real decision-making processes (Guisan et al. 2013). In this study, we used park staff patrolling data for both scientific and management purposes, trying to close this gap in LMNP. In particular, we used maximum-entropy (MaxEnt) algorithms (Phillips et al. 2006) to estimate species distributions, since this technique has been widely used on presence-only data sets, allowing us to estimate habitat suitability for multiple species as a function of certain environmental variables (Wisz et al. 2008, Aguirre-Gutiérrez et al. 2013). By assessing species presence in the Park using camera traps and sightings, we show how camera trap data and data collected during law enforcement patrol activities of park staff can be successfully used to map illegal activities in LMNP. We then discuss how model outputs can be applied for wildlife conservation, identifying priority areas for patrolling and determining species that seem to be most strongly affected by human activities in this remote region.

\section{Material and Methods}

\section{Study Area}

LMNP is in the Myeik Archipelago, Boke Pyin Township, Taninthayi Region, Myanmar $\left(10^{\circ} 50^{\prime} \mathrm{N}, 98^{\circ} 12^{\prime} \mathrm{E}\right)$ and includes the major island of Lampi $\left(205 \mathrm{~km}^{2}\right)$ and 20 smaller islands $(0.3-$ $16.0 \mathrm{~km}^{2}$ in size). LMNP extends two miles from the outer islands, covering a total of $1230 \mathrm{~km}^{2}$, of which $235 \mathrm{~km}^{2}$ are of terrestrial habitats. The islands are covered by tropical lowland wet evergreen forest in the interior, mangrove forest along rivers and freshwater sources and white sandy beach and dune forest along the coasts; other important habitat types are coral reefs, sea-grass beds, freshwater streams and swamps (Giardino et al. 2015). Lampi Island is the core of LMNP, orientated in a north-south direction, with a length of $48 \mathrm{~km}$ and a maximum width of $c$. $6 \mathrm{~km}$. Evergreen forest is the dominant inland vegetation type, characterized by a high level of diversity of plant species, with tree species belonging to the genera Dipterocarpus, Shorea, Vatica and Hopea. Mature trees of species of these genera are scarce, due to illegal selective logging. LMNP is characterized by two community types of mangrove forests along rivers: the Rhizophora apiculata community and the Bruguiera cylindrica community.

\section{Monitoring of Wildlife and Human Disturbance}

The study was carried out using an integrated monitoring approach that involved camera traps to record mammal and reptile presence and both camera traps and patrolling to detect signs of human activity.

Camera traps were used between November 2015 and May 2017 during the dry season (November-May) and were deployed for different periods of time in 72 different locations (Fig. 1). Locations were selected opportunistically to maximize trapping rates of medium to large terrestrial wildlife in different habitat categories and to cover most of the island (Table S1, available online). We concentrated on mammals and reptiles because they were most targeted by poachers. We used Acorn LTL-5310 camera traps, and each camera trap was tied to trees at $c .50 \mathrm{~cm}$ above the ground. Each time the passive infrared (PIR) sensor was activated, camera traps were programmed to record 30 -second videos (at a $1280 \times 720$ pixel resolution) with 1 -minute intervals between consecutive videos, 24 hours a day. Camera trapping was used to make an inventory of the species occurring in the Park; thus, it lacked a robust and systematic sampling design, but it allowed us to monitor most of LMNP. Moreover, opportunistic sightings of mammal species (or their tracks) were recorded by operators along the trails used to access each camera. Unfortunately, most of these sightings lacked a georeferenced location and could not be used for species distribution analysis, but could give confirmatory information about species presence on the island (Table 1).

Human activity in the forest was recorded during patrolling carried out six times per month by the LMNP staff between October 2016 and May 2017. LMNP is divided into six patrol sectors, each covering a different part of the Park, and for each sector the staff covered a trail from 2 to $6 \mathrm{~km}$ long, starting from the beach and entering the forest. The patrolling activities were carried out after Spatial Monitoring and Reporting Tool (SMART) training implemented by the Wildlife Conservation Society (WCS). SMART is a software application that enables one to collect and store data from patrolling in order to enhance the effectiveness and efficiency of the law enforcement and monitoring system of the Park. During patrolling, the occurrence of all illegal activities (e.g., snare traps, forest camps, water extraction and logging) was recorded.

Geographic coordinates were recorded as latitude and longitude (WGS84 datum) for camera trap locations and signs of human activity using a portable GPS receiver (Garmin Dakota 10, Garmin Dakota 20), and then expressed in the Universal Transverse Mercator (UTM/UPS) Coordinate Reference System (fuse 


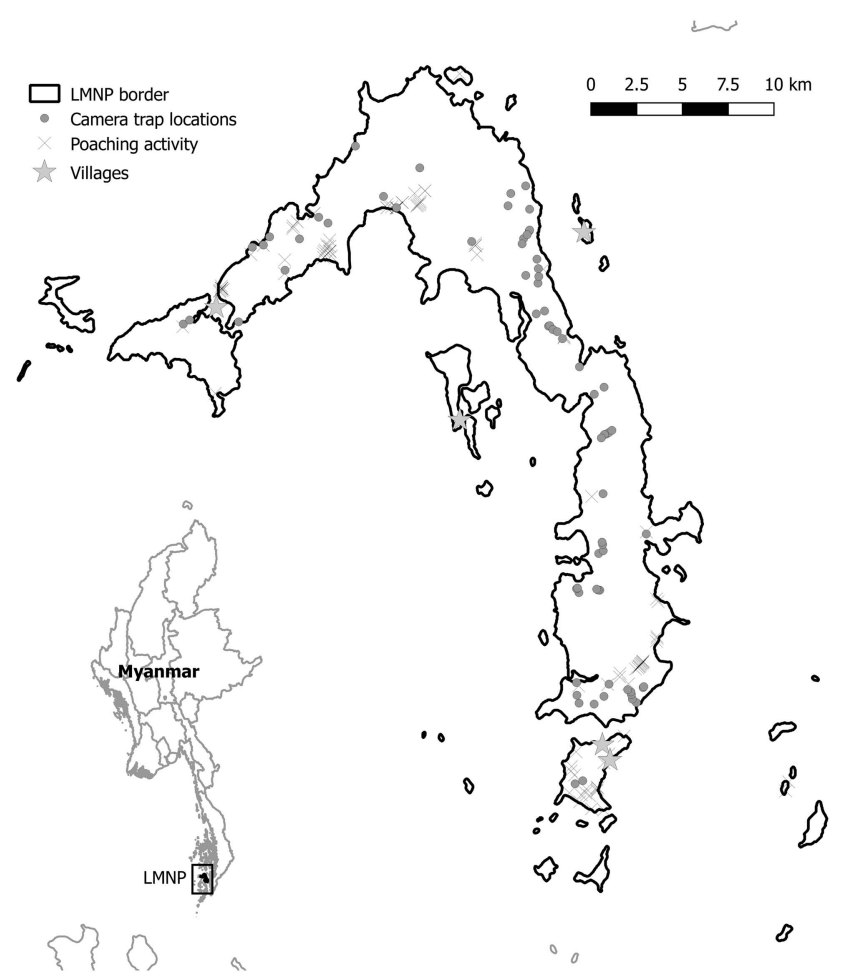

Fig. 1. Mergui and Lampi islands (Myanmar). Dots indicate camera trap locations and crosses show locations of know illegal human activity. LMNP = Lampi Marine National Park.

47 North, WGS84 datum, EPSG code 32647). Data were collected using datasheets specifically developed for the purpose and analysed with the open-source software Quantum GIS (QGIS Development Team 2018).

\section{Species Distribution Modelling}

Species and human distribution were estimated with the MaxEnt algorithm (Phillips et al. 2006) using the R software (R Core Team 2017) and the package 'dismo' (Hijmans et al. 2017). Environmental variables used to predict species distribution were created using a LMNP land cover map produced by Landsat- 8 OLI reflectance data (Giardino et al. 2015), a digital elevation model (SRTM-30 dataset, section 56_10; Reuter et al. 2007) and a distance from rivers raster map, calculated using river signatures detected from the above Landsat- 8 data set (Giardino et al. 2015). Starting from the land cover map, for each habitat category, a 30$\mathrm{m}$ resolution map was produced, calculating the proportion of each habitat category in a circular area with a radius of $200 \mathrm{~m}$. With this procedure, we obtained 11 putative land cover predictors with values ranging between 0 and 1 . As a first step, we calculated variance inflation factors (VIFs) for the 13 putative predictors (11 land cover classes, plus elevation and distance from rivers), and found no collinearities (VIF $<10$ for all ecogeographical variables; Naimi et al. 2014; Table S2). As beaches are not a habitat commonly used by target species, we removed sandy beach and stone beach percentage maps from the set of predictor variables. Moreover, as the area covered by some of the remaining land cover categories was very small and assuming that they could be perceived as a continuum for our target species, we merged four original land-use classes into 'water vegetation' (i.e., 'intertidal areas' + 'mangroves'; Table S2) and 'coastal vegetation' (i.e., 'dune forest' + 'sand vegetation'). With this procedure, we obtained nine final predictors (Table 2) - VIFs for the new set of predictors show that variables did not have collinearity problems (Table S3).

MaxEnt was run using its default configuration, as is often done when calculating multi-species models, making model finetuning for each species impractical (Merow et al. 2013).

MaxEnt 'raw' output provides a continuous raster (with values ranging from 0 to 1 ): we transformed these continuous maps into binary estimated distribution maps considering as 'estimated presence' for the cells containing values greater than or equal to a threshold maximizing the sum of sensitivity (i.e., the percentage of correctly predicted presence cells) and specificity (i.e., the percentage of correctly predicted absence cells; Fielding \& Bell 1997). We chose this threshold among the several available since it is one of the most accurate (Liu et al. 2005) and has been successfully used in other multi-species approaches (Algar et al. 2009, Buisson et al. 2010, Dubuis et al. 2011, Fitzpatrick et al. 2011, Di Febbraro et al. 2016). This allowed binary 'estimated presence/absence' maps to be drawn, obtaining a more perceivable representation that can be useful at the decision-making level (Slocum 1999).

For each species estimated distribution model, the proportion of contribution of each ecogeographical variable was taken into account, and the overall slope of the response curve was used to judge whether the effect of a single variable increased or decreased the estimated suitability value. Even if MaxEnt allows model fitting with a low number of presence points, we did not create estimated distribution models for species with fewer than nine presence points; moreover, species with area under the receiver operating characteristic curve (AUC) values (indicating probability that the model prediction is correct; Fielding \& Bell 1997) under 0.7 were not considered for further analysis (e.g., Baldwin 2009). Final binary estimated distribution raster maps were used to calculate the proportion of overlap between species and human distribution as a percentage ((surface area of intersection between target species and human distribution/human distribution surface area) $\times 100)$.

\section{Results}

Camera traps operated for $33.4 \pm 14.4$ days (mean \pm SD) at each location. Combining camera trapping and sightings, we recorded 19 different terrestrial vertebrate species (18 mammals and 1 reptile) for a total of 1270 presence points. We recorded three small mammal species (two Muridae and one Tupaiidae), five species of squirrels, four species of primates (three Cercopithecidae and one Lorisidae), two Cetartiodactyla (one Suidae and one Tragulidae), three carnivores (one Mustelidae and two Viverridae) and the Sunda pangolin (Manidae, Manis javanica). The only reptile species observed was the common water monitor (Varanus salvator), included in models because it is subject to poaching. Five of these species are considered as Near Threatened or Vulnerable (International Union for Conservation of Nature (IUCN) Red List criteria: http://iucnredlist.org), while the Sunda pangolin is considered Critically Endangered (Table 1).

The Sunda pangolin, northern treeshrew and Indochinese ground squirrel models had AUC values of 0.55, 0.54 and 0.51, respectively. Since their estimated distributions would not be significantly different from a random distribution (Baldwin 2009), these species were excluded from further analysis. 
Table 1. Species detected in Lampi Marine National Park using camera traps and opportunistic sightings. For each species, the number of georeferenced points (n of localization), the distribution model area under the receiver operating characteristic curve (AUC) and the overlap in percentage between the species distribution model and human activity distribution model (\% poaching activity overlap) are reported

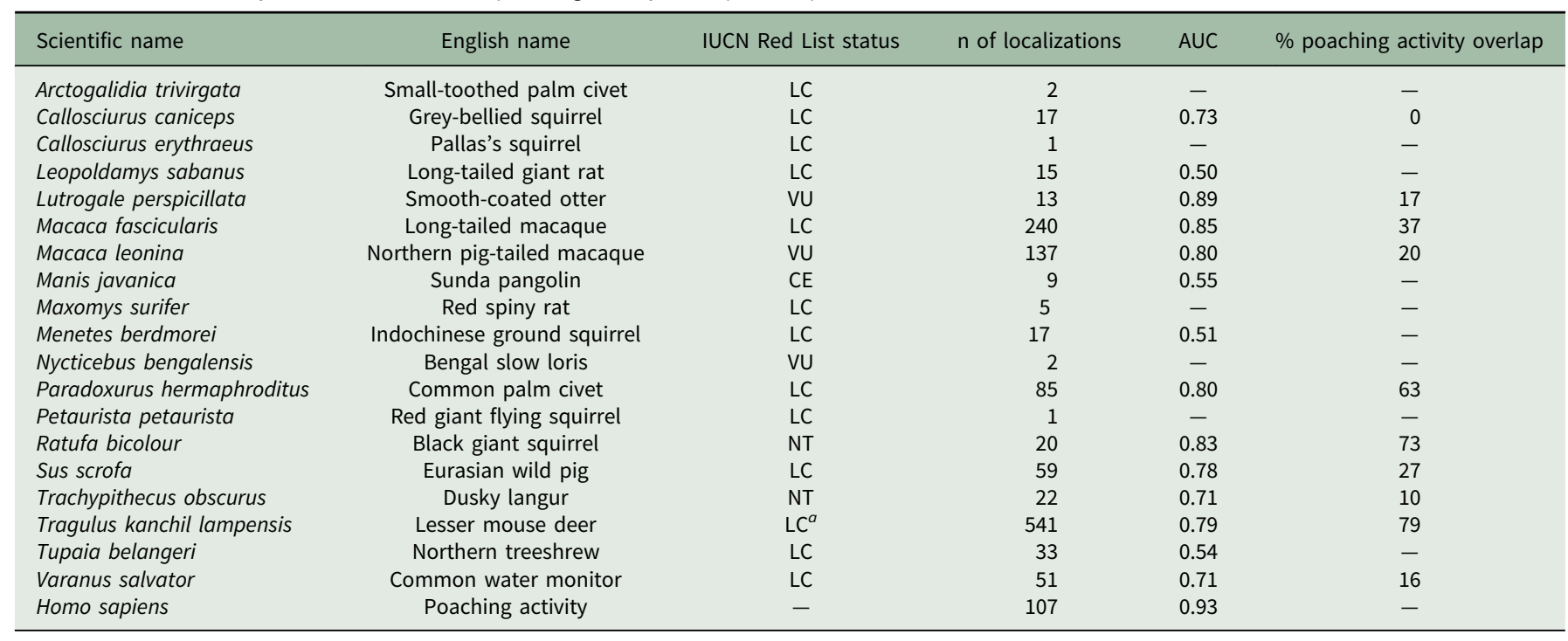

${ }^{a}$ IUCN status refers to the species as $T$. kanchil

$\mathrm{CE}=$ Critically Endangered; IUCN = International Union for Conservation of Nature; $\mathrm{LC}=$ Least Concern; NT $=$ Near Threatened; VU $=\mathrm{Vulnerable}$

A total of 107 human presence signs were recorded (Fig. 2) and used to estimated human distribution: 37 snare traps, 28 abandoned camps, 20 signs of logging activities, 18 active camps and 4 signs of water extraction. There were overlaps between the human activities estimated distribution maps and each SDM (Table 1). The two species that had the greatest overlap with human activities estimated distribution were two least-concern species that are quite widespread in LMNP, namely the common palm civet and the lesser mouse deer (subspecies lampensis), but other more threatened species such as the black giant squirrel (Near Threatened) and the northern pig-tailed macaque (Vulnerable) also had overlaps with human activities.

The relative contributions of the environmental predictors used varied for each species; elevation, evergreen forest and distance from river were the most important for the majority of species (Table 2). The relationship with evergreen forest was positive for most species, while distance from river was always negative.

\section{Discussion}

The combined use of camera traps with occasional sightings made it possible to increase the number of species detected in LMNP, since cameras set just above ground level cannot reliably detect arboreal species (e.g., Pallas's squirrel, Bengal slow loris). Silveira et al. (2003) showed how track surveying is the most time-efficient method for detecting species presence, followed by line transects and camera trapping. Since population surveys had never previously been attempted in LMNP, we included opportunistic sightings because an integrated monitoring approach was more cost effective in collecting species presence information.

Estimated distribution models improved the knowledge of the presence and distribution of some of the LMNP species and helped with evaluating the risk associated with human pressures. In this particular situation, due to non-systematic presence-only data collection and the small sample size, the models presented here could be biased, but MaxEnt is perhaps the most popular and repeatable approach to making such comparisons; it is widely used (e.g., Rödder \& Lötters 2009, Roscioni et al. 2013, 2014, Russo et al. 2014, 2015, Mayol et al. 2015) and tends to perform better than other similar techniques (Elith et al. 2006, Thorn et al. 2009, Jackson \& Robertson 2011, Bosso et al. 2013, RamirezVillegas et al. 2014, McCarthy et al. 2015), and a fair spatial coverage of the most utilized areas useful for management and law enforcement was achieved.

We recorded the presence of globally threatened and rare species such as the northern pig-tailed macaque, populations of which in Myanmar are declining because of logging, habitat loss, hunting and trade (Boonratana et al. 2008), and the smoothcoated otter, which is threatened by loss of wetland habitats due to infrastructure construction and agriculture, reduction in prey biomass, poaching and contamination of waterways by pesticides (de Silva et al. 2015). The presence of these species and proven illegal activities should put LMNP in the spotlight; the decline of Asian tropical forest mammal populations in general because of trade-backed poaching (Ceballos \& Ehrlich 2002, Corlett 2007, Schipper et al. 2008) could be repeated in LMNP.

Similarly, the Bengal slow loris is also a vulnerable species that is mainly threatened by habitat loss and fragmentation, but also by hunting and illegal trade (for meat, traditional medicine and the pet trade) of this nocturnal primate's populations (Nekaris \& Nijman 2007, Streicher et al. 2008).

An important record was the presence of the critically endangered Sunda pangolin, which is listed as a 'Completely Protected Animal' in Myanmar under the Protection and Conservation of Natural Areas law (1994). Sunda pangolin populations are estimated to have fallen rapidly in recent decades because of habitat loss and hunting to supply the international trade for live pangolins, skins, scales and meat (Challender \& MacMillan 2014, Zhang et al. 2015). In particular, Myanmar plays a key role in supplying pangolin scales and live animals for international trade to China (Challender et al. 2014, Nijman et al. 2016). Regrettably, the Sunda pangolin and slow loris models did 


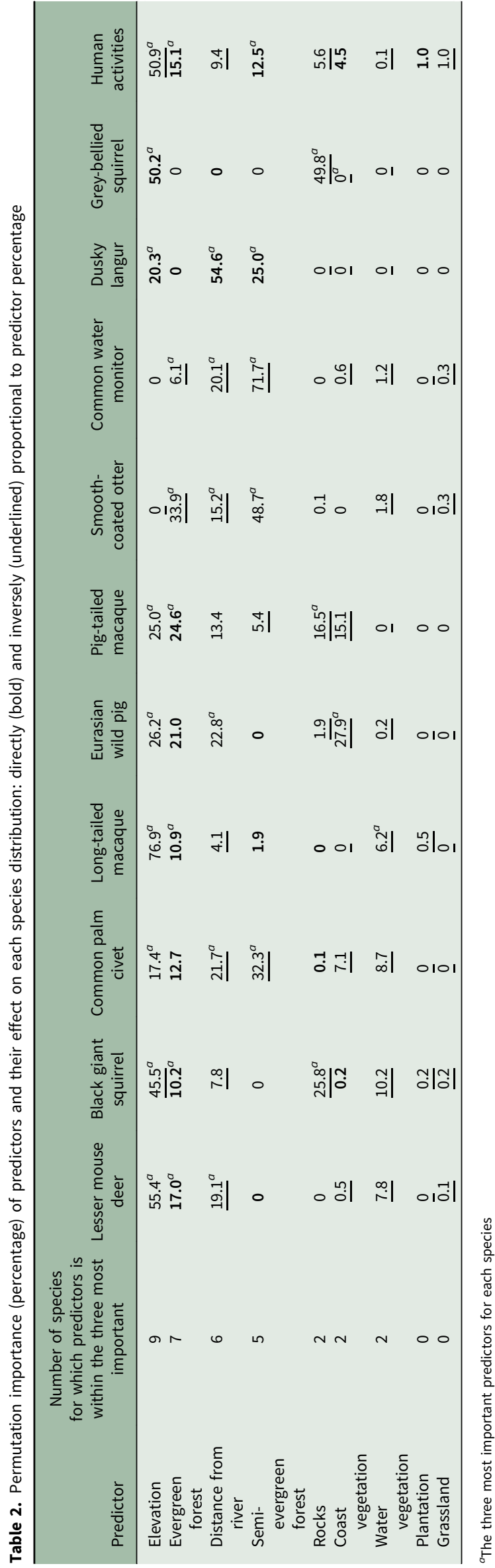

not perform well enough to be reliable: indeed, we obtained a low AUC for the former species and we recorded only two sightings of the latter, probably due to its arboreal and nocturnal habits.

Another potential issue for LMNP conservation could be that animals - or parts of them - are commercialized for traditional medicine, not only for the Chinese market but also inside Myanmar, particularly towards the neighbouring Mon region (Nijman \& Sheperd 2017). Nijman and Shepherd (2017) found that in Kyaiktiyo market 16 different species were sold for traditional medicine, some of which are also hunted in LMNP (Macaca spp., Trachypithecus spp., Manis spp.). Marine fauna could also be vulnerable: during our research in LMNP, fishing vessels encroached on no fishing areas, and species such as the Irrawaddy dolphin (Orcaella brevirostris) could be endangered due to exploitation for the local traditional medicine market. Our results confirm LMNP as an important protected area for marine species as well.

To model the distribution of human illegal activities inside the Park, we used pictures of people taken by camera traps and tracks and signs recorded during patrolling. The patrolling recorded illegal activities such as logging or hunting, which are forbidden within LMNP as per notification no. 40/696 that established the protected area, granting access to the main island exclusively to local residents. We suppose that a considerable amount of the illegal activities are carried out by people coming by sea from outside the Park: locals should not need to camp there for hunting or logging, yet we found several unauthorized forest camps. Being able to compare the human estimated distribution with that of wildlife offered an opportunity to identify areas susceptible to anthropogenic risks.

Illegal hunters in LMNP mostly target the lesser mouse deer and the Eurasian wild pig as meat sources for locals and markets, while the common water monitor is hunted not just for its meat, but especially for the value of its skin in the leather trade and its fat for traditional medicine (Bennet et al. 2010). Even if these species are classified as of Least Concern by the IUCN, hunters often use unselective traps to catch these animals, since snaring requires less effort and time than active hunting. Hence, even if hunting activities are not directly targeting the endangered species present in the area, trapping can have serious effects on their persistence, eventually causing shifts in the faunal species composition (Jerozolimski \& Peres 2003, Corlett 2007). In fact, most of the species models overlapped with the estimated human distribution and for some species overlap was high. In particular, the black giant squirrel (a Near Threatened species) overlapped for most of its distribution (73\%), and the pig-tailed macaque (Vulnerable) overlapped for $20 \%$ of its range in the area. Despite the highly specific habitat requirements of both the smooth-coated otter and the dusky langur (coastal and deep forest, respectively), $10-17 \%$ of their distribution was also part of the human distribution. This is evidence of potential risk not just for hunted species, but also for those that may not be directly targeted for hunting purposes, but that overlap with human activity areas. Three-quarters of Khao National Park (Thailand) is considered to be natural, yet people continue to enter the Park and poachers spend weeks in the forest setting up semi-permanent field camps, as in LMNP (Jenks et al. 2012). There the presence of more ranger stations would help to reduce poaching activities, but it would be better to increase patrol activities in inaccessible areas (Jenks et al. 2012). Law enforcement is probably the main problem for nature conservation in protected areas. We planned routine patrolling activities with LMNP staff; the next step will be to test whether 

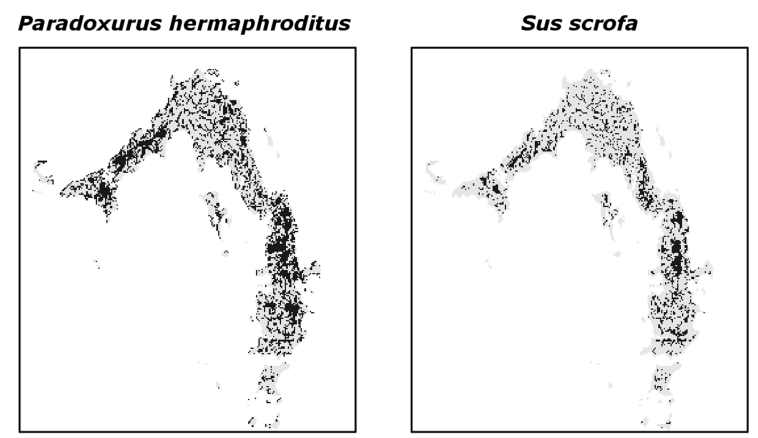

Macaca fascicularis
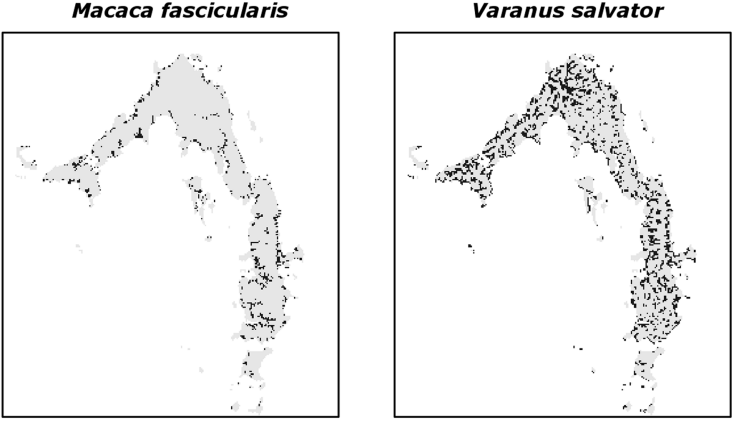

Human activity

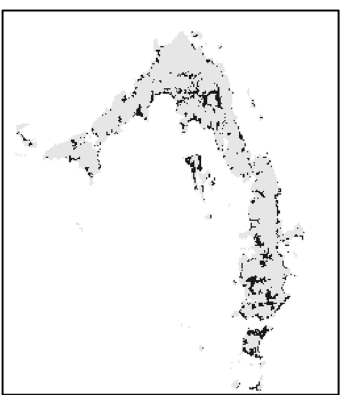

Tragulus kanchil lampensis

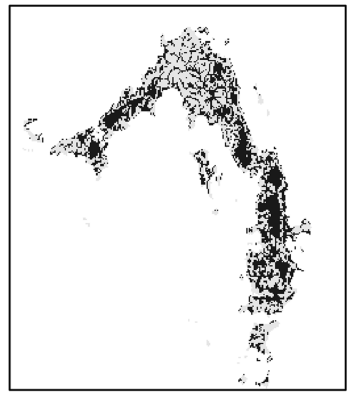

Macaca leonina

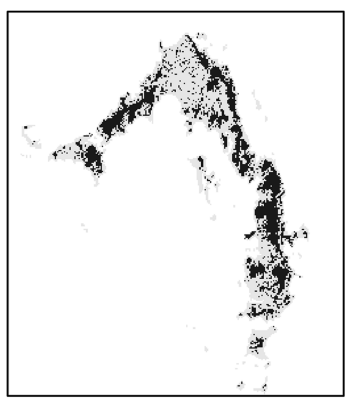

Fig. 2. Species estimated distributions (dark grey) obtained with maximum-entropy modelling.

this approach is efficient at reducing illegal human activities in future.

Questionnaires and interviews have been widely used to learn about the exploitation of forest resources, but may underestimate real poaching and logging rates (Weladji \& Tchamba 2003, Rao et al. 2005, Knapp et al. 2010, Steinmetz et al. 2014). Signs recorded by patrols and cameras showed that human activities are widely distributed in the Park, and areas more selected by people are those at lower elevations and mainly in evergreen or semievergreen forests. Villages occur at lower elevations close to the shore, making lower-elevation forests more accessible to people; the two forest habitats selected are those where most of the species occur.

Although distance from rivers was not among the most important environmental variables, especially in the human presence model, it was often negatively correlated with species suitability (i.e., greater distances corresponded with lower probability of human activities, whereas distance from a river often has a negative effect on suitability for wildlife). Tropical forests are sometimes difficult to access, and walking into the forest requires time and energy, especially when trails are not available as in LMNP. Hence, rivers represent a faster and easier way not just to cross the forest and reach its heart, but also to transport logs and prey back to the villages, especially during the rainy season, when stream levels rise. This information is of great importance in identifying areas potentially threatened by human impacts and could allow special attention to be directed to the river while patrolling, as well as in planning conservation actions.

\section{Conclusions}

Georeferenced human presence signs recorded by patrolling and camera traps can be a viable approach to identifying the real risk associated with illegal activities in natural areas. Our results indicate that LMNP is valuable in terms of habitat types, species richness and composition. Its conservation effectiveness may be improved in the future thanks to better targeting of management activities such as enforcement and direct compensation payments to local communities; patrol activities alone will not be effective, and engagement of local communities will be of fundamental importance in the coming years. The outcomes of modelling the estimated presence of both wildlife and humans proved useful here to identifying 'areas of conflict'; such an approach could also help to identify zones where the development of alternative income sources for local people might be focused, such as tourism regulated in order to minimize impacts 
on pristine areas, limiting stresses on biodiversity, but also offering local people a real alternative to poaching (Jenks et al. 2012).

Supplementary Material. For supplementary material accompanying this paper, visit www.cambridge.org/core/journals/environmental-conservation

Acknowledgements. We are grateful to Peter Brakels (Istituto Oikos) and Anna Giovannini (University of Insubria), who contributed to data collection in 2016 and 2017. We also appreciate the technical cooperation of the LMNP personnel rangers, foresters and forest guards involved in the monitoring and patrolling activities. The research in the LMNP has been realized with the help of Lara Beffasti and Elisa Facchini (Istituto Oikos).

Financial Support. This work was part of the project 'COAST: Rafforzare le capacità locali per la COnservazione Ambientale e lo Sviluppo del Turismo nell'arcipelago di Myeik' - AID 0101178/OIKOS/BUR, financed by the Italian Ministry of Foreign Affairs.

Conflict of Interest. None.

Ethical Standards. None.

\section{References}

Aguirre-Gutiérrez J, Carvalheiro LG, Polce C, van Loon EE, Raes N, et al. (2013) Fit-for-purpose: species distribution model performance depends on evaluation criteria - Dutch hoverflies as a case study. PLoS One 8(5): e63708.

Ahumada JA, Silva CEF, Gajapersad K, Hallam C, Hurtado J, et al. (2011) Community structure and diversity of tropical forest mammals: data from a global camera trap network. Philosophical Transactions of the Royal Society B: Biological Sciences 366: 2703-2711.

Algar AC, Kharouba HM, Young ER, Kerr JT (2009) Predicting the future of species diversity: macroecological theory, climate change, and direct tests of alternative forecasting methods. Ecography 32: 22-23.

Aung M, Khaing Swe K, Oo T, Kyaw Moe K, Leimgruber P, et al. (2004) The environmental history of Chatthin Wildlife Sanctuary, a protected area in Myanmar (Burma). Journal of Environmental Management 72: 205-216.

Baldwin RA (2009) Use of maximum entropy modeling in wildlife research. Entropy 11: 854-866.

Bennet D, Gaulke M, Pianka ER, Somaweera R, Sweet SS (2010) Varanus salvator. The IUCN Red List of Threatened Species e.T178214A7499172. URL http://dx.doi.org/10.2305/IUCN.UK.2010-4.RLTS.T178214A7 499172.en

Boonratana R, Das J, Yongcheng L, Htun S, Timmins RJ (2008) Macaca leonina. The IUCN Red List of Threatened Species e.T39792A10257933. URL http://dx.doi.org/10.2305/IUCN.UK.2008.RLTS.T39792A10257933.en

Bosso L, Rebelo H, Garonna AP, Russo D (2013) Modelling geographic distribution and detecting conservation gaps in Italy for the threatened beetle Rosalia alpina. Journal for Nature Conservation 21: 72-80.

Brook BW, Sodhi NS, Ng PKL (2003) Catastrophic extinctions follow deforestation in Singapore. Nature 424: 420-426.

Buisson L, Thuiller W, Casajus N, Lek S, Grenouillet G (2010) Uncertainty in ensemble forecasting of species distribution. Global Change Biology 16: $1145-1157$.

Cayuela L, Golicher DJ, Newton AC, Kolb M, De Alburquerque FS, et al. (2009) Species distribution modeling in the tropics: problems, potentialities, and the role of biological data for effective species conservation. Tropical Conservation Science 2: 319-352.

Ceballos G, Ehrlich PR (2002) Mammal population losses and the extinction crisis. Science 296: 904-907.

Ceballos G, Ehrlich PR, Soberon J, Salazar I, Fay JP (2005) Global mammal conservation: what must we manage? Science 309: 603-607

Challender D, Nguyen Van T, Shepherd C, Krishnasamy K, Wang A, et al. (2014) Manis javanica. The IUCN Red List of Threatened Species e. T12763A45222303. URL http://dx.doi.org/10.2305/IUCN.UK.2014-2.RLTS. T12763A45222303.en
Challender DWS, MacMillan DC (2014) Poaching is more than an enforcement problem. Conservation Letters 7: 484-494.

Corlett RT (2007) The impact of hunting on the mammalian fauna of tropical Asian forests. Biotropica 39: 292-303.

de Silva P, Khan WA, Kanchanasaka B, Reza Lubis I, Feeroz MM, Al-Sheikhly OF (2015) Lutrogale perspicillatae. The IUCN Red List of Threatened Species T12427A21934884. URL http://dx.doi.org/10.2305/IUCN.UK.20152.RLTS.T12427A21934884.en

Di Febbraro M, Martinoli A, Russo D, Preatoni D, Bertolino S (2016) Modelling the effects of climate change on the risk of invasion by alien squirrels. Hystrix 27: 22-29.

Di Marco M, Boitani L, Mallon D, Hoffmann M, Iacucci A, et al. (2014) A retrospective evaluation of the global decline of carnivores and ungulates: global decline of carnivores and ungulates. Conservation Biology 28: 1109-1118.

Dubuis A, Pottier J, Rion V, Pellissier L, Theurillat JP, Guisan A (2011) Predicting spatial patterns of plant species richness: a comparison of direct macroecological and species stacking modelling approaches. Diversity and Distribution 17: 1122-1131.

Elith J, Graham CH, Anderson RP, Dudík M, Ferrier S, et al. (2006) Novel methods improve prediction of species' distributions from occurrence data. Ecography 29: 129-151.

Fa JE, Peres CA, Meeuwig J (2002) Bushmeat exploitation in tropical forests: an intercontinental comparison. Conservation Biology 16: 232-237.

Ferrier S (2002) Mapping spatial pattern in biodiversity for regional conservation planning: where to from here? Systematic biology 51: 331-363.

Fielding A, Bell J (1997) A review of methods for the assessment of prediction errors in conservation presence/absence models. Environmental Conservation 24: 38-49.

Fitzpatrick MC, Sanders NJ, Ferrier S, Longino JT, Weiser MD, Dunn R (2011) Forecasting the future of biodiversity: a test of single-and multispecies models for ants in North America. Ecography 34: 836-847.

Fordham DA, Brook BW (2010) Why tropical island endemics are acutely susceptible to global change. Biodiversity and Conservation 19: 329-342.

Funk VA, Richardson KS (2002) Systematic data in biodiversity studies: use it or lose it. Systematic biology 51: 303-316.

Giardino C, Bresciani M, Fava F, Matta E, Brando VE, Colombo R (2015) Mapping submerged habitats and mangroves of Lampi Island Marine National Park (Myanmar) from in situ and satellite observations. Remote Sensing 8: 2.

Gomes-Vale C, Campos JC, Silva TL, Gonçalves DV, Sow AS, et al. (2016) Biogeography and conservation of mammals from the West Sahara-Sahel: an application of ecological niche-based models and GIS. Hystrix, 27: 30-37.

Graham CH, Moritz C, Williams SE (2006) Habitat history improves prediction of biodiversity in rainforest fauna. Proceedings of the National Academy of Sciences of the United States of America 103: 632-636.

Guisan A, Tingley R, Baumgartner JB, Naujokaitis-Lewis I, Sutcliffe PR, et al. (2013). Predicting species distributions for conservation decisions. Ecology Letters 16: 1424-1435.

Hijmans RJ, Phillips SJ, Leathwick J, Elith J (2017) dismo: Species Distribution Modeling. R package version 1.1-4. URL https://CRAN.R-project.org/ package $=$ dismo

Jackson CR, Robertson MP (2011) Predicting the potential distribution of an endangered cryptic subterranean mammal from few occurrence records. Journal for Nature Conservation 19: 87-94.

Jenks KE, Howard J, Leimgruber P (2012) Do ranger stations deter poaching activity in national parks in Thailand? Biotropica 44: 826-833.

Jerozolimski A, Peres CA (2003) Bringing home the biggest bacon: a cross-site analysis of the structure of hunter-kill profiles in Neotropical forests. Biological Conservation 111: 415-425.

Knapp EJ, Rentsch D, Schmitt J, Lewis C, Polasky S (2010) A tale of three villages: choosing an effective method for assessing poaching levels in western Serengeti, Tanzania. Oryx 44: 178-184.

Laurance WF, Carolina Useche D, Rendeiro J, Kalka M, Bradshaw CJA, et al. (2012) Averting biodiversity collapse in tropical forest protected areas. Nature 489: 290-294. 
Linkie M, Chapron G, Martyr DJ, Holden J, leader-Williams N (2006) Assessing the viability of tiger subpopulations in a fragmented landscape. Journal of Applied Ecology 43: 576-586.

Liu C, Berry P, Dawson T, Pearson RG (2005) Selecting thresholds of occurrence in the prediction of species distributions. Ecography 3: 385-393.

Margules CR, Pressey RL (2000) Systematic conservation planning. Nature 405: 243-253.

Mayol M, Riba M, González-Martínez SC, Bagnoli F, Beaulieu JL, et al. (2015) Adapting through glacial cycles: insights from a long-lived tree (Taxus baccata). New Phytologist 208: 973-986.

McCarthy JL, Wibisono HT, McCarthy KP, Fuller TK, Andayani N (2015) Assessing the distribution and habitat use of four felid species in Bukit Barisan Selatan National Park, Sumatra, Indonesia. Global Ecology and Conservation 3: 210-221.

Meijaard E, Sheil D, Nasi R, Augeri D, Rosenbaum B, et al. (2005) Life after Logging: Reconciling Wildlife Conservation and Production Forestry in Indonesian Borneo. Jakarta, Indonesia: Center for International Forestry Research (CIFOR).

Merow C, Smith MJ, Silander JA (2013) A practical guide to MaxEnt for modeling species' distributions: what it does, and why inputs and settings matter. Ecography 36: 1058-1069.

Milton O, Estes RD (1963) Myanmar Wildlife Survey: 1959-1960. New York, NY, USA: International Union for Conservation of Nature and Natural Resources and the American Committee for International Wildlife Protection.

Naimi B, Hamm NAS, Groen TA, Skidmore AK, Toxopeus AG (2014) Where is positional uncertainty a problem for species distribution modelling? Ecography 37: 191-203.

Nekaris KAI, Nijman V (2007) CITES proposal highlights rarity of asian nocturnal primates (Lorisidae: Nycticebus). Folia Primatologica 78: 211-214.

Nijman V, Shepherd CR (2017) Ethnozoological assessment of animals used by Mon traditional medicine vendors at Kyaiktiyo, Myanmar. Journal of ethnopharmacology 206: 101-106.

Nijman V, Zhang MX, Shepherd CR (2016) Pangolin trade in the Mong La wildlife market and the role of Myanmar in the smuggling of pangolins into China. Global Ecology and Conservation 5: 118-126.

Pearson RG, Dawson TP (2003) Predicting the impacts of climate change on the distribution of species: are bioclimate envelope models useful? Global Ecology \& Biogeography 12: 361-371.

Phillips SJ, Anderson RP, Schapire RE (2006) Maximum entropy modeling of species geographic distributions. Ecological Modelling 190: 231-259.

QGIS Development Team (2018) QGIS Geographic Information System. Open Source Geospatial Foundation Project. URL https:/qgis.org/en/site/

Ramirez-Villegas J, Cuesta F, Devenish C, Peralvo M, Jarvis A, Arnillas CA (2014) Using species distributions models for designing conservation strategies of Tropical Andean biodiversity under climate change. Journal for Nature Conservation 22: 391-404.

Rao M, Htun S, Zaw T, Myint T (2010) Hunting, livelihoods and declining wildlife in the Hponkanrazi Wildlife Sanctuary, North Myanmar. Environmental Management 46: 143-153.

Rao M, Myint T, Zaw T, Htun S (2005) Hunting patterns in tropical forests adjoining the Hkakaborazi National Park, north Myanmar. Oryx 39: 292-300.

Rao M, Rabinowitz A, Khaing ST (2002) Status review of the protected-area system in Myanmar, with recommendations for conservation planning. Conservation Biology 16: 360-368.

Reuter HI, Nelson A, Jarvis A, (2007) An evaluation of void filling interpolation methods for SRTM data. International Journal of Geographic Information Science 21: 983-1008.
Rödder D, Lötters S (2009) Niche shift versus niche conservatism? Climatic characteristics of the native and invasive ranges of the Mediterranean house gecko (Hemidactylus turcicus). Global Ecology and Biogeography 18: 674-687.

Roscioni F, Rebelo H, Russo D, Carranza ML, Di Febbraro M, Loy A (2014) A modelling approach to infer the effects of wind farms on landscape connectivity for bats. Landscape Ecology 29: 891-903.

Roscioni F, Russo D, Di Febbraro M, Frate L, Carranza ML, Loy A (2013) Regional scale modelling of the cumulative impact of wind farms on bats. Biodiversity and Conservation 22: 1821-1835.

Rosenzweig M. (1995) Species Diversity in Space and Time. Cambridge, UK: Cambridge University Press.

Russo D, Di Febbraro M, Cistrone L, Jones G, Smeraldo S, et al. (2015) Protecting one, protecting both? Scale-dependent ecological differences in two species using dead trees, the Rosalia longicorn beetle and the barbastelle bat. Journal of Zoology 297: 165-175.

Russo D, Di Febbraro M, Rebelo H, Mucedda M, Cistrone L, et al. (2014) What story does geographic separation of insular bats tell? A case study on Sardinian Rhinolophids. PLoS One 9: e110894.

Schipper J, Chanson JS, Chiozza F, Cox NA, Hoffmann M, et al. (2008) The status of the world's land and marine mammals: diversity, threat, and knowledge. Science 322: 225-230.

Silveira L, Jácomo ATA, Diniz-Filho JAF (2003) Camera trap, line transect census and track surveys: a comparative evaluation. Biological Conservation 114: 351-355.

Slocum TA (1999). Thematic Cartography and Visualization. Upper Saddle River, NJ, USA: Prentice-Hall.

Soe KM, Swe Pyi P, Zin T (2010) Lampi Marine National Park Mammal Survey Research Report. Hlaing Township, Yangon, Myanmar: Biodiversity and Nature Conservation Association (BANCA) and Nature and Wildlife Conservation Division (NWCD).

Steinmetz R, Srirattanaporn S, Mor-Tip J., Seuaturien N (2014) Can community outreach alleviate poaching pressure and recover wildlife in South-East Asian protected areas? Journal of Applied Ecology 51: 1469-1478.

Streicher U, Singh M, Timmins RJ, Brockelman W (2008) Nycticebus bengalensis. The IUCN Red List of Threatened Species e. T39758A10263081. URL http://dx.doi.org/10.2305/IUCN.UK.2008.RLTS. T39758A10263081.en

Thorn JS, Nijman V, Smith D, Nekaris KAI (2009) Ecological niche modelling as a technique for assessing threats and setting conservation priorities for Asian slow lorises (Primates: Nycticebus). Diversity and Distributions 15: 289-298.

Vié J.-C, Hilton-Taylor C, Stuart SN (2009) Wildlife in a Changing World: An Analysis of the 2008 IUCN Red List of Threatened Species. Gland, Switzerland: IUCN.

Visconti P, Pressey RL, Giorgini D, Maiorano L, Bakkenes M, et al. (2011) Future hotspots of terrestrial mammal loss. Philosophical Transactions of the Royal Society B: Biological Sciences 366: 2693-2702.

Weladji RB, Tchamba MN (2003) Conflict between people and protected areas within the Bénoué Wildlife Conservation Area, North Cameroon. Oryx 37: 72-79.

Wisz MS, Hijmans RJ, Li J, Peterson AT, Graham CH, Guisan A, NCEAS Predicting Species Distributions Working Group (2008) Effects of sample size on the performance of species distribution models. Diversity and Distributions 14: 763-773.

Zhang H, Miller MP, Yang F, Chan HK, Gaubert P, Ades G, Fischer GA (2015) Molecular tracing of confiscated pangolin scales for conservation and illegal trade monitoring in Southeast Asia. Global Ecology and Conservation 4: 414-422. 